\title{
Red blood cell transfusion and outcomes in patients with acute lung injury, sepsis and shock
}

\author{
Elizabeth C Parsons ${ }^{1 *}$, Catherine L Hough ${ }^{1}$, Christopher W Seymour ${ }^{2}$, Colin R Cooke ${ }^{3}$, Gordon D Rubenfeld ${ }^{4}$ and
} Timothy R Watkins ${ }^{1,5}$, for the NHLBI ARDS Network

\begin{abstract}
Introduction: In this study, we sought to determine the association between red blood cell (RBC) transfusion and outcomes in patients with acute lung injury (ALI), sepsis and shock.

Methods: We performed a secondary analysis of new-onset ALI patients enrolled in the Acute Respiratory Distress Syndrome Network Fluid and Catheter Treatment Trial (2000 to 2005) who had a documented ALI risk factor of sepsis or pneumonia and met shock criteria (mean arterial pressure (MAP) $<60 \mathrm{mmHg}$ or vasopressor use) within 24 hours of randomization. Using multivariable logistic regression, we examined the association between RBC transfusion and 28-day mortality after adjustment for age, sex, race, randomization arm and Acute Physiology and Chronic Health Evaluation III score. Secondary end points included 90-day mortality and ventilator-free days (VFDs). Finally, we examined these end points among the subset of subjects meeting prespecified transfusion criteria defined by five simultaneous indicators: hemoglobin $<10.2 \mathrm{~g} / \mathrm{dL}$, central or mixed venous oxygen saturation < $70 \%$, central venous pressure $\geq 8 \mathrm{mmHg}$, MAP $\geq 65 \mathrm{mmHg}$, and vasopressor use.

Results: We identified 285 subjects with ALI, sepsis, shock and transfusion data. Of these, 85 also met the above prespecified transfusion criteria. Fifty-three (19\%) of the two hundred eighty-five subjects with shock and twenty (24\%) of the subset meeting the transfusion criteria received RBC transfusion within twenty-four hours of randomization. We found no independent association between RBC transfusion and 28-day mortality (odds ratio = $1.49,95 \% \mathrm{Cl}(95 \%$ confidence interval) $=0.77$ to $2.90 ; P=0.23$ ) or VFDs (mean difference $=-0.35,95 \% \mathrm{Cl}=-4.03$ to 3.32; $P=0.85$ ). Likewise, 90 -day mortality and VFDs did not differ by transfusion status. Among the subset of patients meeting the transfusion criteria, we found no independent association between transfusion and mortality or VFDs.
\end{abstract}

Conclusions: In patients with new-onset ALI, sepsis and shock, we found no independent association between RBC transfusion and mortality or VFDs. The physiological criteria did not identify patients more likely to be transfused or to benefit from transfusion.

Keywords: erythrocyte transfusion, respiratory distress syndrome, adult therapy, sepsis therapy, treatment outcome, intensive care unit, respiration, artificial

\section{Introduction}

Red blood cell (RBC) transfusion is common in the ICU, with nearly half of all critically ill patients receiving at least one transfusion during their ICU stay [1]. However, it is not clear that $\mathrm{RBC}$ transfusion improves patient outcomes. The use of RBC transfusion varies widely

\footnotetext{
* Correspondence: parsonse@u.washington.edu

'Division of Pulmonary and Critical Care Medicine, University of Washington,

Harborview Medical Center, 325 Ninth Avenue, Seattle, WA 98104, USA

Full list of author information is available at the end of the article
}

among physicians, with high rates of potentially unnecessary transfusions [1]. Several lines of evidence indicate that routine $\mathrm{RBC}$ transfusion in critically ill patients is associated with excess harm, including the development of nosocomial infection $[2,3]$, acute lung injury (ALI) $[4,5]$ and death $[3,6-8]$.

Despite evidence linking RBC transfusion to adverse clinical outcomes and recommendations for lower transfusion thresholds, certain critically ill patients may benefit from RBC transfusion. RBC transfusions might

\section{() Biomed Central}


benefit patients with sepsis by improving oxygen delivery while patients are in a state of high metabolic demand and overall oxygen deficit. A randomized, controlled trial supported this notion by demonstrating that an early goal-directed resuscitation protocol, including fluids, inotropes and RBC transfusion (at a hematocrit threshold of $<30 \%$ ) saved lives when administered within 6 hours after severe sepsis diagnosis in the emergency department setting [9]. These results are in contrast to earlier studies of hemodynamically driven strategies aimed at supranormal oxygen delivery in the ICU, which failed to improve outcomes $[10,11]$.

Conflicting evidence regarding $\mathrm{RBC}$ transfusion and outcomes has led to significant controversy over the use of RBC transfusion in goal-directed sepsis resuscitation strategies and in critically ill septic patients in the ICU $[12,13]$. A 2007 survey found that only $0.1 \%$ of responding physicians complied with all 2004 Surviving Sepsis Campaign guidelines advocating use of a goal-directed sepsis bundle that included RBC transfusion along with other therapeutics within the first 6 hours of resuscitation [14]. In this survey, protocol-driven RBC transfusion varied from $15 \%$ to $70 \%$ [14]. Current practice guidelines [12,13] do not address the use of RBC transfusion beyond the first 6 hours after sepsis diagnosis, despite evidence that in $43 \%$ of patients, the objectives of goal-directed therapy may not be initiated or completed within this time interval [15]. Furthermore, the effect of RBC transfusion on clinical outcomes in ICU patients with septic shock complicated by coexistent ALI is unknown. The Fluid and Catheter Treatment Trial (FACTT) trial showed that liberal volume administration (which could include RBC transfusion) was associated with poor outcomes in hemodynamically stable ALI patients [16], but the primary analysis did not examine the specific association between transfusion and clinical outcomes. In this study, we examined whether RBC transfusion administered in the ICU to patients with a recent diagnosis of ALI, sepsis and shock is independently associated with death and/or the number of days free from mechanical ventilation. We also investigated whether a prespecified set of physiological criteria might help identify a subset of patients most likely to receive or benefit from transfusion.

\section{Materials and methods}

We performed a secondary analysis of the Acute Respiratory Distress Syndrome Network (ARDSNet) FACTT, a multicenter, randomized, controlled trial comparing the effectiveness of two fluid management and invasive monitoring strategies $[16,17]$ performed between 2000 and 2005. FACTT enrolled 1,000 subjects within 48 hours of a new ALI diagnosis (mean time 24 hours at a median of 48 hours after hospital admission).
All subjects were randomized to a liberal or conservative fluid management strategy and a pulmonary artery catheter or central venous catheter for 7 days or until they achieved unassisted ventilation. During periods of shock (defined as mean arterial pressure (MAP) $<60$ $\mathrm{mmHg}$ or vasopressor use), fluid management was not dictated by the study protocol and left to the discretion of the clinician. Transfusion was not a part of the FACTT protocol and was initiated according to the physician's discretion. During the primary FACTT study, written informed consent was obtained from participants or legally authorized surrogates. All required data elements for our secondary analysis were available in their entirety from the FACTT database, acquired with permission from ARDSNet and the National Heart, Lung, and Blood Institute (NHLBI). The Institutional Review Board of the University of Washington approved this secondary data analysis and waived the need for additional consent.

\section{Eligibility and definitions}

We first identified subjects with sepsis and shock within the FACTT database. We defined "sepsis" as the presence of a documented ALI risk factor for sepsis or pneumonia (Figure 1). We excluded subjects with a documented ALI risk factor for trauma or multiple transfusions, as well as those missing transfusion data during the first 24 hours after randomization. We defined "sepsis and shock" (hereinafter referred to as "shock") as a mean arterial pressure (MAP) $<60 \mathrm{mmHg}$ or vasopressor use within the first 24 hours after randomization. Finally, we identified a subgroup of subjects with shock meeting four physiological criteria that might identify those subjects most likely to benefit from RBC transfusion (Figure 1). These criteria, derived from a sepsis resuscitation trial [9], included (1) adequate volume and pressor support, defined as central venous pressure (CVP) $\geq 8 \mathrm{mmHg}, \mathrm{MAP} \geq 65 \mathrm{mmHg}$ and use of a vasopressor; (2) poor perfusion, defined as central venous oxygen saturation $\left(\mathrm{cVO}_{2}\right)$ or mixed venous oxygen saturation $\left(\mathrm{mVO}_{2}\right)<70 \%$; and (3) anemia, defined as hemoglobin $(\mathrm{Hb})<10.2 \mathrm{~g} / \mathrm{dL}$.

\section{Data collection}

Trained research coordinators collected demographic and clinical data prospectively during the FACTT study. These data included center, randomization arm, age, sex, race, location, APACHE III score 24 hours prior to randomization, baseline comorbidities, ratio of oxygen pressure to fraction of inspired oxygen $\left(\mathrm{PaO}_{2} / \mathrm{FiO}_{2}\right.$ ratio), $\mathrm{Hb}$ and ventilatory parameters, including static pressure and tidal volume. In addition, detailed hemodynamic information was abstracted, including vasopressor use, MAP, $\mathrm{cVO}_{2}, \mathrm{mVO}_{2}$ and volume of fluid and blood products. 


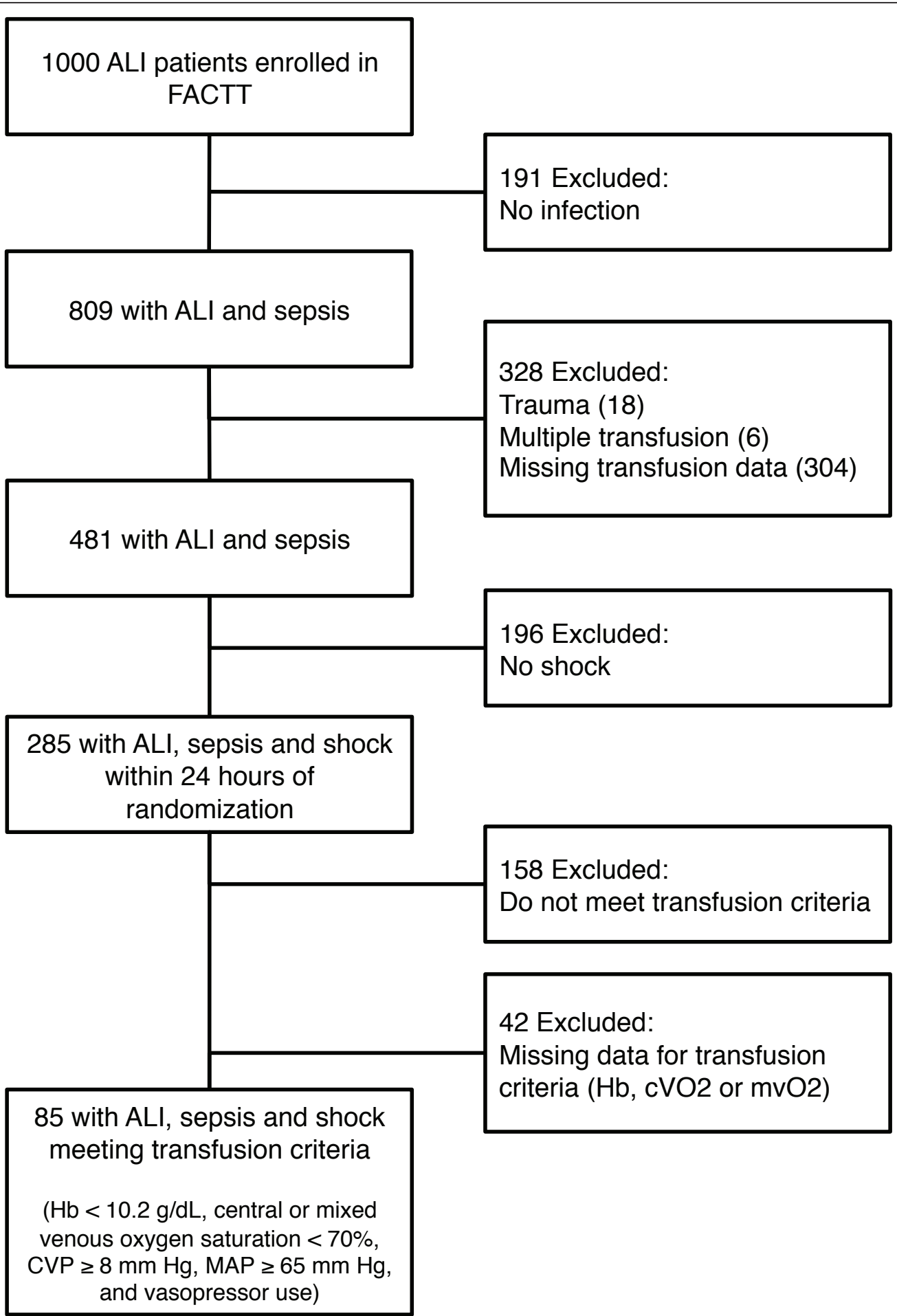

Figure 1 Derivation of analysis cohorts. ALI, acute lung injury; FACTT, Fluid and Catheter Treatment Trial; $\mathrm{Hb}$, hemoglobin; $\mathrm{CVO}_{2}$, central venous oxygen saturation; $\mathrm{mVO}_{2}$, mixed venous oxygen saturation; CVP, central venous pressure; MAP, mean arterial pressure.

\section{Exposure}

Transfusion data recorded at 8:00 AM daily through study day 8 were the number of packed RBC units transfused during the preceding 24 hours. Our goal was to examine the association between RBC transfusion and outcomes in subjects with a new ALI diagnosis who also met the criteria for sepsis and shock. We therefore restricted our transfusion exposure window to the first 
24 hours after study randomization (a maximum of 72 hours after ALI diagnosis).

\section{Outcomes}

The primary outcome was the proportion of patients who died before hospital discharge and within 28 days after study enrollment (28-day mortality). Patients were monitored during follow-up for 90 days or until death or discharge to home with unassisted breathing. Secondary outcomes were 90-day mortality and number of ventilator-free days (VFDs) by days 28 and 90 as previously defined [18].

\section{Statistical analysis}

We performed bivariate comparisons between subjects who did or did not receive RBC transfusions using $t$ tests with unequal variance or Wilcoxon rank-sum tests for continuous variables and $\chi^{2}$ tests for categorical variables. To assess the independent association between $\mathrm{RBC}$ transfusion and mortality at 28 and 90 days, we performed multivariable logistic regression, adjusting for factors which we considered potentially related to both outcomes and the likelihood of transfusion, including subject age $[1,19,20]$, sex $[19,20]$, race $[19,21]$, APACHE III score and FACTT randomization arm [16]. To examine the association between RBC transfusion and VFDs, we performed multivariable negative binomial regression adjusted for the same predetermined confounders by using graphical analysis of predicted to observed probabilities and likelihood ratio testing to demonstrate goodness of fit. We then performed marginal means estimation to determine the adjusted difference in mean VFDs by transfusion status to assess goodness of fit using a log-likelihood ratio test [22].

Because of the prevalence of missing data for transfusion, we performed multiple imputation by chained equations to account for missing data [23-25]. Additional details regarding our imputation methods are given in Additional files 1 and 2. We repeated our primary analysis in the imputed cohort using Rubin's rules to generate combined risk estimates across the imputed datasets [26]. All statistical analyses were performed using Stata 11.0 software (State Corp., College Station, TX, USA).

\section{Results}

Derivation of the analysis cohorts

Of the 1,000 subjects enrolled in FACTT, 809 (81\%) had ALI and a documented risk factor of sepsis and/or pneumonia. We excluded 328 subjects (33\%) with an ALI risk factor of trauma (18 subjects), multiple transfusion (6 subjects) or missing transfusion data (304 subjects). We identified 285 subjects who met our criteria for shock within the first 24 hours after randomization
(Figure 1). Of these 285 subjects, 85 (30\%) met all transfusion indicators outlined above.

\section{Baseline characteristics}

Fifty-three (19\%) of the two hundred eighty-five subjects with shock were transfused within twenty-four hours of randomization, which occurred at a median of 1 day (interquartile range (IQR) 1 to 2 days) after ICU admission and a median of 2 days (IQR 1 to 5 days) after hospital admission. Transfused and nontransfused subjects were similar in terms of age, sex, ICU location, comorbidities, $\mathrm{PaO}_{2} / \mathrm{FiO}_{2}$ ratio and randomization arm (Table 1). In bivariate comparisons, transfusion was associated with black race $(28 \%$ vs. $17 \% ; P=0.03)$, higher APACHE III score (mean 118 vs. 103; $P<0.01$ ), more fluid administration in the first 24 hours (mean 6.8 vs. $5.5 \mathrm{~L} ; P=0.01$ ) and lower baseline $\mathrm{Hb}$ (mean 8.5 vs. 9.7 $\mathrm{g} / \mathrm{dL} ; P<0.01)$.

\section{Outcomes}

Twenty-three transfused subjects $(43 \%)$ died by day 28 compared with 70 nontransfused subjects $(30 \%)(P=$ 0.06). By day 28 , median VFDs were zero (IQR 0 to 19 ) in transfused subjects and 9 (IQR 0 to 19) in nontransfused subjects $(P=0.35)$. In multivariable regression analysis, we observed no independent association between transfusion and 28-day mortality (adjusted odds ratio $(\mathrm{OR})=1.49,95 \% \mathrm{CI}=0.77$ to $2.90 ; P=0.23$ ) or VFDs (adjusted mean difference $=-0.35,95 \% \mathrm{CI}=-4.03$ to $3.32, P=0.85$ ) (Table 2). Likewise, we observed no independent association between transfusion and 90-day mortality (adjusted $\mathrm{OR}=1.55,95 \% \mathrm{CI}=0.81$ to $2.96 ; P$ $=0.19$ ) or VFDs (adjusted difference $=-10.1,95 \% \mathrm{CI}=$ -23.6 to $3.42 ; P=0.14$ ) (Table 2). These results were not appreciably changed after performing multiple imputation of missing data (Additional file 2).

\section{Subset analysis among subjects meeting transfusion criteria}

In the subset of subjects meeting our prespecified transfusion criteria, only 20 (24\%) received RBC transfusions during the exposure period of interest. Bivariate analyses of subject characteristics by transfusion status are shown in Table 3. Within this subgroup, transfusion was associated with older age (mean age $=65$ vs. 51 years; $P<0.01)$ male sex $(65 \%$ vs. $38 \% ; P=0.04)$, greater APACHE III scores (median $=122$ vs. $103 ; P=$ 0.02 ) and lower $\mathrm{Hb}$ (mean $=8.2$ vs. $9.0 \mathrm{~g} / \mathrm{dL} ; P=0.02$ ). Death by day 28 occurred in $10(50 \%)$ of the transfused subjects compared to 19 (29\%) of the nontransfused subjects $(P=0.09)$. By day 28 , median VFDs were zero (IQR 0 to 12.5) in transfused subjects and nine (IQR 0 to 19$)$ in nontransfused subjects $(P=0.26)$. In multivariable regression analysis, after adjusting for our 
Table 1 Subject characteristics in shock

\begin{tabular}{|c|c|c|c|}
\hline Characteristics & Transfused $(n=53)$ & Not transfused $(n=232)$ & $P$ value \\
\hline Age, years & $53(17)$ & $52(16)$ & 0.52 \\
\hline Males & $30(57)$ & $123(53)$ & 0.22 \\
\hline \multicolumn{4}{|l|}{ Race } \\
\hline White & $35(66)$ & $149(64)$ & 0.03 \\
\hline Black & $15(28)$ & $40(17)$ & \\
\hline Other & $3(6)$ & $43(19)$ & \\
\hline \multicolumn{4}{|l|}{ Chronic comorbidities } \\
\hline Diabetes & $11(21)$ & $40(18)$ & 0.59 \\
\hline Hepatic failure & $2(4)$ & $1(0.4)$ & 0.03 \\
\hline Alcohol use & $2(4)$ & $26(12)$ & 0.13 \\
\hline Prior myocardial infarction & $0(0)$ & $11(5)$ & 0.12 \\
\hline Congestive heart failure & $0(0)$ & $8(4)$ & 0.18 \\
\hline \multicolumn{4}{|l|}{ Admission type } \\
\hline Medical ICU & $47(89)$ & $211(91)$ & 0.87 \\
\hline Surgical ICU & $5(9)$ & $18(8)$ & \\
\hline Other & $1(2)$ & $3(1)$ & \\
\hline \multicolumn{4}{|l|}{ Randomization } \\
\hline Liberal fluid (vs. conservative) & $25(47)$ & $114(49)$ & 0.80 \\
\hline Pulmonary artery (vs. central venous) catheter & $28(53)$ & $125(54)$ & 0.89 \\
\hline APACHE III score & $118(27)$ & $103(2)$ & $<0.01$ \\
\hline Days from ALI diagnosis to randomization & $0(0,1)$ & $0(0,1)$ & 0.99 \\
\hline Days from hospital admission to randomization & $2(1,7)$ & $2(1,4)$ & 0.18 \\
\hline Days from ICU admission to randomization & $1(1,2)$ & $1(1,2)$ & 0.89 \\
\hline $\mathrm{PaO}_{2} / \mathrm{FiO}_{2}$ ratio at randomization & 107 (63 to 150$)$ & 108 (73 to 154$)$ & 0.47 \\
\hline \multicolumn{4}{|l|}{ Physiological parameters during exposure window } \\
\hline Hemoglobin nadir, g/dL & $8.5(1.4)$ & $9.7(1.4)$ & $<0.01$ \\
\hline $\mathrm{CVO}_{2} / \mathrm{mVO}_{2}$ ratio nadir & $67(12)$ & $67(13)$ & 0.76 \\
\hline MAP nadir, mmHg & $62(8)$ & $63(9)$ & 0.47 \\
\hline Mean MAP, mmHg & $71(8)$ & $73(9)$ & 0.19 \\
\hline Total fluid received, $\mathrm{L}$ & $6.8(4.4)$ & $5.5(3.2)$ & 0.01 \\
\hline Multiple pressors & $27(51)$ & $120(52)$ & 0.92 \\
\hline
\end{tabular}

APACHE III, Acute Physiology and Chronic Health Evaluation III; ALI, acute lung injury; $\mathrm{CVO}_{2}$, central venous oxygen saturation (\%); mVO saturation (\%); MAP, mean arterial pressure $(\mathrm{mmHg})$. Estimates are reported as $n(\%)$, means (SD) or medians (IQR) as appropriate.

predetermined confounders, we observed no independent association between transfusion and 28-day mortality (adjusted OR $=2.23,95 \% \mathrm{CI}=0.63$ to $7.81 ; P=$

Table 2 Outcomes with red blood cell transfusion among subjects with shock

\begin{tabular}{lcc}
\hline Parameter & $\begin{array}{c}\text { Adjusted estimate } \\
\mathbf{C l})\end{array}$ & $\begin{array}{c}\boldsymbol{P} \\
\text { value }\end{array}$ \\
\hline $\begin{array}{l}\text { Odds ratio for death } \\
\text { At } 28 \text { days }\end{array}$ & $1.49(0.77$ to 2.90$)$ & 0.23 \\
$\quad$ At 90 days & $1.55(0.81$ to 2.96$)$ & 0.19 \\
$\begin{array}{l}\text { Difference in mean ventilator-free } \\
\text { days }\end{array}$ & $-0.35(-4.03$ to 3.32$)$ & 0.85 \\
$\quad$ Days 1 to 28 & $-10.1(-23.6$ to 3.42$)$ & 0.14 \\
\hline Days 1 to 90 &
\end{tabular}

${ }^{a}$ Adjusted for age, gender, race, Acute Physiology and Chronic Health Evaluation III score and randomization arm. $95 \% \mathrm{Cl}, 95 \%$ confidence interval. Data in center column are odds ratio or marginal means estimates $(95 \% \mathrm{Cl})$.
0.21 ) or VFDs (adjusted difference $=-1.34,95 \% \mathrm{CI}=$ -7.50 to $4.82 ; P=0.67$ ) (Table 4 ). Likewise, we observed no independent association between RBC transfusion and 90-day mortality (adjusted $\mathrm{OR}=2.16$, 95\% CI, 0.66 to $7.01 ; P=0.20$ ) or VFDs (adjusted difference $=-18.4,95 \% \mathrm{CI}=-43.6$ to $6.76 ; P=0.15$ ) (Table 4). These results were not appreciably changed after performing multiple imputation of missing data (Additional file 2).

\section{Discussion}

The purpose of our study was to determine whether $\mathrm{RBC}$ transfusion administered in the ICU is associated with outcomes among patients with a recent diagnosis of ALI, sepsis and shock. We found that RBC transfusion in this period occurred in approximately one in five patients. The proportion of patients receiving $R B C$ transfusions was similar in the subgroup of patients 
Table 3 Subject characteristics in shock meeting physiological criteria for transfusion

\begin{tabular}{|c|c|c|c|}
\hline Characteristics & Transfused $(n=20)$ & Not transfused $(n=65)$ & $P$ value \\
\hline Age, years & $65(15)$ & $51(14)$ & $<0.01$ \\
\hline Male & $13(65)$ & $25(38)$ & 0.04 \\
\hline \multicolumn{4}{|l|}{ Race } \\
\hline White & $14(70)$ & $45(69)$ & 0.49 \\
\hline Black & $5(25)$ & $11(17)$ & \\
\hline Other & $1(5)$ & $9(14)$ & \\
\hline \multicolumn{4}{|l|}{ Chronic comorbidities } \\
\hline Diabetes & $5(26)$ & $14(22)$ & 0.71 \\
\hline Hepatic failure & $1(5)$ & $0(0)$ & 0.07 \\
\hline Alcohol use & $0(0)$ & $9(14)$ & 0.09 \\
\hline Prior myocardial infarction & $0(0)$ & $3(5)$ & 0.39 \\
\hline Congestive heart failure & $0(0)$ & $5(8)$ & 0.26 \\
\hline \multicolumn{4}{|l|}{ Admission type } \\
\hline Medical & $16(80)$ & $61(94)$ & 0.08 \\
\hline Surgical & $4(20)$ & $4(6)$ & \\
\hline Other & $0(0)$ & $0(0)$ & \\
\hline \multicolumn{4}{|l|}{ Randomization arm } \\
\hline Liberal fluid (vs. conservative) & $11(55)$ & $29(45)$ & 0.42 \\
\hline Pulmonary artery (vs. central venous) catheter & $14(70)$ & $46(71)$ & 0.95 \\
\hline APACHE III score & $122(7)$ & $103(3)$ & 0.02 \\
\hline Days from ALI diagnosis to randomization & $1(0$ to 1$)$ & $1(0$ to 1$)$ & 0.96 \\
\hline Days from hospital admission to randomization & $2(1$ to 11$)$ & $2(1$ to 4$)$ & 0.49 \\
\hline Days from ICU admission to randomization & $1(0.5$ to 1.5$)$ & 1 (1 to 2$)$ & 0.20 \\
\hline $\mathrm{PaO}_{2} / \mathrm{FiO}_{2}$ ratio at randomization & 107 (60 to 144$)$ & 89 (66 to 152$)$ & 0.85 \\
\hline \multicolumn{4}{|l|}{ Physiological parameters during exposure window } \\
\hline Hemoglobin nadir, g/dL & $8.2(1.2)$ & $9.0(0.8)$ & 0.02 \\
\hline $\mathrm{cVO}_{2} / \mathrm{mVO}_{2}$ ratio nadir & $59(1)$ & $59(10)$ & 0.99 \\
\hline MAP nadir & $62(7)$ & $62(9)$ & 0.80 \\
\hline Mean MAP & $72(8)$ & $73(7)$ & 0.70 \\
\hline Multiple pressors & $12(60)$ & $32(49)$ & 0.45 \\
\hline Total fluid received, L & $5.4(3.0)$ & $5.0(2.9)$ & 0.54 \\
\hline
\end{tabular}

APACHE III, Acute Physiology and Chronic Health Evaluation III; ALI, acute lung injury; $\mathrm{PaO}_{2} / \mathrm{FiO}_{2}$, ratio of arterial oxygen pressure to fraction of inspired oxygen; $\mathrm{CVO}_{2}$, central venous oxygen saturation (\%); $\mathrm{mVO}_{2}$, mixed venous oxygen saturation (\%); MAP, mean arterial pressure (mmHg). Estimates are reported as $n(\%)$, means (SD) or medians (IQR) as appropriate.

Table 4 Outcomes with red blood cell transfusion among subjects with shock meeting physiological criteria for transfusion $^{\text {a }}$

\begin{tabular}{|c|c|c|}
\hline Parameter & $\begin{array}{l}\text { Adjusted estimate }(95 \% \\
\qquad \mathrm{Cl})^{\mathrm{b}}\end{array}$ & $\begin{array}{c}P \\
\text { value }\end{array}$ \\
\hline \multicolumn{3}{|l|}{ Odds ratio for death } \\
\hline At 28 days & 2.23 (0.63 to 7.81$)$ & 0.21 \\
\hline At 90 days & 2.16 (0.66 to 7.01$)$ & 0.20 \\
\hline \multicolumn{3}{|c|}{$\begin{array}{l}\text { Difference in mean ventilator-free } \\
\text { days }\end{array}$} \\
\hline Days 1 to 28 & $-1.34(-7.50$ to 4.82$)$ & 0.67 \\
\hline Days 1 to 90 & $-18.4(-43.6$ to 6.76$)$ & 0.15 \\
\hline \multicolumn{3}{|c|}{$\begin{array}{l}\text { a Transfusion criteria were defined by five simultaneous indicators: hemoglobin } \\
<10.2 \mathrm{~g} / \mathrm{dL} \text {, central or mixed venous oxygen saturation }<70 \% \text {, central venous } \\
\text { pressure } \geq 8 \mathrm{mmHg}, \mathrm{MAP} \geq 65 \mathrm{mmHg} \text { and vasopressor use. }{ }^{\mathrm{b}} \text { Adjusted for } \\
\text { age, gender, race, Acute Physiology and Chronic Health Evaluation III score } \\
\text { and randomization arm. Data in center column are odds ratio or marginal } \\
\text { means estimates }(95 \% \mathrm{Cl}) \text {. }\end{array}$} \\
\hline
\end{tabular}

meeting our specified transfusion criteria. After adjusting for predetermined confounders, we found no significant, independent association between RBC transfusion and mortality or VFDs. The $95 \%$ CIs surrounding our risk estimates argue that the lack of statistical significance should be interpreted cautiously, as our risk estimates included clinically relevant differences in the direction of both benefit and harm.

Our study failed to show benefit or harm when RBC transfusion was administered to patients with a new diagnosis of ALI, sepsis and shock. There are several potential explanations for this result. First, RBC transfusion in this study was administered to patients in the ICU up to 72 hours after they met the criteria for sepsis and ALI. The clinical setting and/or timing of RBC transfusion may in fact be important in determining its benefit or harm $[5,9,27,28]$. A single randomized trial 
published by Rivers et al. [9] showed a mortality benefit when $\mathrm{RBC}$ transfusion was administered to patients with severe sepsis in the emergency department as part of a larger goal-directed resuscitation strategy that included fluid and vasopressor support. This resuscitation protocol was administered to enrolled subjects in an emergency department setting within 6 hours after a sepsis diagnosis. Thereafter, subjects were admitted to an ICU and underwent care as determined by their physicians. Notably, $64 \%$ of subjects in the treatment arm of the Rivers et al. trial were exposed to RBC transfusion within the first 6 hours of therapy. In contrast, observational studies in the ICU have not consistently demonstrated that RBC transfusion improves oxygen delivery in fluid-replete septic subjects [28-30] and instead raises concern regarding increased complications, including nosocomial infection [2,3,31], ALI [3-5,8] and death $[3,6-8,32]$. In an observational study of 160 ICU patients with septic shock, delayed goal-directed resuscitation and transfusion up to 48 hours after diagnosis were associated with higher risk of ALI [5]. Similarly to these observational studies, our findings may reflect a lack of benefit when transfusion is administered beyond the initial 6-hour resuscitation window or for reasons other than protocol-driven resuscitation in severe sepsis. Finally, RBC transfusion may carry minimal beneficial effects or even harmful effects on patient outcomes independently of other resuscitative strategies, such as volume resuscitation or vasopressor support.

Despite our efforts to identify a subset of subjects with shock whom transfusion might benefit, we observed no improvement in outcomes with RBC transfusion. Although transfusion criteria were met in one of four subjects, we observed no treatment association when adjusting for these factors in subgroup analysis. Consistent with prior work [28-30,33], our study suggests that physiological indicators may not necessarily identify those patients likely to benefit from $\mathrm{RBC}$ transfusion. While randomized data in patients with septic shock are lacking, there is growing experimental evidence that transfusion of stored RBCs can potentially harm patients with preexisting inflammation or impaired microvascular perfusion. According to the current "two-hit" hypothesis of transfusion injury [34], RBC units may contain bioactive particles capable of influencing the cellular injury that leads to organ failure in susceptible patients with preexisting insults such as sepsis or mechanical ventilation $[4,34,35]$. In addition, in vivo models have demonstrated that older RBC units exhibit reduced deformability [36,37], which may actually impair capillary flow and oxygen delivery in an already compromised microvascular system $[38,39]$. It is therefore possible that RBC transfusion administered beyond the first 6 hours of illness may paradoxically be harmful in the very patients that we hope will benefit.

Our study has several limitations. First, transfusion data for a significant number of subjects were missing. Because complete case analysis in the setting of missing data may be limited by both reduced power and residual bias $[23,26]$, we performed a sensitivity analysis using multiple imputation of missing values, which provided results similar to our primary analysis. The combination of missing RBC transfusion data and the small proportion of patients who met our "shock" definition limited our study's power to detect statistically significant associations between transfusion and outcomes (minimum detectable difference in mortality $=19 \%$ based on an overall mortality rate of $30 \%$ and two-sided $\alpha=0.05$ ). While pooled blood products such as fresh frozen plasma (FFP) may also have an effect on patient outcomes, missing data and low FFP transfusion rates in our cohort precluded our ability to include FFP as a meaningful covariate. Furthermore, we cannot exclude the possibility of residual bias related to unignorable missing data (missing not at random) or other covariates either not present or insufficiently captured in the database, including age of transfused blood [40], the indication for transfusion, concomitant therapies such as fluid administration and the manner in which transfusion was administered. Though we carefully defined sepsis, shock and physiological criteria on the basis of objective measures within a fixed time period, misclassification of shock due to etiologies other than sepsis is a potential limitation of our study. We also could not determine the reason why physicians chose to transfuse individuals or whether transfusion was administered concomitantly with other resuscitation strategies. The decision to administer RBC transfusion may depend on a host of factors, including patient-, hospital- and provider-level characteristics $[1,14]$. Understanding factors that contribute to transfusion practice variability is an important avenue of future study, because blood products are a limited and costly health care resource. Last, our study cannot determine whether RBC transfusion is a meaningful component of early goal-directed therapy within the first 6 hours of severe sepsis. It is important to note that our patients likely differed significantly, with regard to their stage of illness, indication for transfusion and concomitant therapy, from those enrolled in the randomized trial evaluating early goal-directed therapy in the emergency department setting [9]. Nonetheless, some form of goal-directed resuscitation likely extends beyond the first 6 hours of severe sepsis into the ICU period. Previous work suggests that delayed goal-directed therapy may be associated with increased complications in critically ill septic patients [5]. Despite its limitations, our study builds on previous work suggesting that RBC 
transfusion beyond 6 hours of presentation may not improve mortality in critically ill patients with septic shock and coexistent ALI and that physiological criteria may not identify those patients likely to benefit from transfusion in the ICU setting.

\section{Conclusions}

We did not observe a statistically significant benefit or harm associated with RBC transfusion among patients with a recent diagnosis of ALI, sepsis and shock. In addition, there was no statistically significant difference in outcomes among the subset of subjects meeting prespecified physiological transfusion criteria. While not meeting statistical significance, our observed risk estimates do not exclude the possibility of clinically relevant transfusion-related benefit or harm. These data add to our understanding of the use of RBC transfusion in patients with a recent diagnosis of ALI undergoing resuscitation in the ICU, suggesting that physiological indicators may not identify those patients likely to benefit from transfusion therapy. Future studies are needed to verify these results in larger cohorts to account for potential modifiers, including age of transfused blood and other resuscitative strategies.

\section{Key messages}

- RBC transfusion is of unclear benefit to patients with established ALI and severe sepsis.

- In this study, physiological criteria did not identify patients more likely to be transfused or to benefit from transfusion.

- Future studies are needed to examine potential modifiers, including age of transfused blood and other resuscitative strategies.

\section{Additional material}

\section{Additional file 1: Methods for Missing Data Analysis. This file}

presents subject characteristics among patients with shock, according to the presence or absence of RBC transfusion data. It also details the methods used for multiple imputation of missing data for RBC transfusion and other covariates. Table E1 Subject characteristics in shock by the presence or absence of transfusion data. ALI, acute lung injury; APACHE III, Acute Physiology and Chronic Health Evaluation III; MICU, medical ICU; SICU, surgical ICU; $\mathrm{PaO}_{2} / \mathrm{FiO}_{2}$, ratio of arterial oxygen pressure to fraction of inspired oxygen; $\mathrm{CVO}_{2} / \mathrm{mVO}_{2}$, ratio of central venous oxygen saturation to mixed venous oxygen saturation; MAP, mean arterial pressure; SD, standard deviation; IQR, interquartile range. Table E2 Imputation variables with number of missing values in subjects with shock. ALI, acute lung injury; MICE, multiple imputation using chained equations; FACTT, Fluid and Catheter Treatment Trial; APACHE III, Acute Physiology and Chronic Health Evaluation III; MICU, medical ICU; SICU, surgical ICU; $\mathrm{PaO}_{2} / \mathrm{FiO}_{2}$, ratio of arterial oxygen pressure to fraction of inspired oxygen; $\mathrm{PaO}_{2}$, arterial oxygen pressure; $\mathrm{PaCO}_{2}$, arterial carbon dioxide pressure; BUN, blood urea nitrogen; MAP, mean arterial pressure; CVP, central venous pressure.

Additional file 2: Results of Imputation Analysis. This file presents the results of multivariate regression analysis performed in the imputation cohort. Table E3 Outcomes with red blood cell transfusion among subjects with sepsis and shock within the imputation cohort. ALI, acute lung injury; 95\% Cl, 95\% confidence interval; APACHE III, Acute Physiology and Chronic Health Evaluation III.

\section{Abbreviations}

ALl: acute lung injury; APACHE III: Acute Physiology and Chronic Health Evaluation III; $\mathrm{CVO}_{2}$ : central venous oxygen saturation; FACTT: Fluid and Catheter Treatment Trial; MAP: mean arterial pressure; $\mathrm{mVO}_{2}$ : mixed venous oxygen saturation; RBC: red blood cell.

\section{Acknowledgements}

The FACTT study was supported by contracts (N01-HR 46046-64 and N01HR-16146-54) with the NHLBI. Dr. Parsons is supported by National Institutes of Health T32 training grant HL007287. Dr. Watkins is supported by a grant from the National Institute of General Medical Sciences (NIGMS) (K23GM086729). This work was performed at Harborview Medical Center, Seattle, WA, USA.

\section{Author details}

'Division of Pulmonary and Critical Care Medicine, University of Washington, Harborview Medical Center, 325 Ninth Avenue, Seattle, WA 98104, USA. ${ }^{2}$ Departments of Critical Care and Emergency Medicine, University of Pittsburgh, 3550 Terrace Street, Pittsburgh, PA 15261, USA. ${ }^{3}$ Division of Pulmonary and Critical Care Medicine and Robert Wood Johnson Foundation Clinical Scholars Program, University of Michigan, 1150 West Medical Center Drive, Ann Arbor, Ml 48109, USA. ${ }^{4}$ Program of Trauma, Critical Care and Emergency Medicine, Sunnybrook Health Sciences Centre, University of Toronto, 2075 Bayview Avenue, Toronto, ON, M4N 3M5, Canada. ${ }^{5}$ Research Institute, Puget Sound Blood Center, 921 Terry Avenue, Seattle, WA 98104, USA.

\section{Authors' contributions}

EP participated in the study design, data acquisition, statistical analysis and data interpretation and also drafted the manuscript. $\mathrm{CH}$ participated in the statistical analysis, data interpretation and manuscript revision. CW and CC participated in the multiple imputation analysis and manuscript revision. GR participated in study conception and revised the manuscript critically for important intellectual content. TW participated in study conception, study design, statistical analysis, data interpretation and manuscript revision. All authors read and approved the final manuscript.

\section{Competing interests}

The authors declare that they have no competing interests.

Received: 27 May 2011 Revised: 25 July 2011

Accepted: 21 September 2011 Published: 21 September 2011

\section{References}

1. Corwin HL, Gettinger A, Pearl RG, Fink MP, Levy MM, Abraham E, Maclntyre NR, Shabot MM, Duh MS, Shapiro MJ: The CRIT Study: anemia and blood transfusion in the critically ill. Current clinical practice in the United States. Crit Care Med 2004, 32:39-52.

2. Shorr AF, Jackson WL, Kelly KM, Fu M, Kollef MH: Transfusion practice and blood stream infections in critically ill patients. Chest 2005, 127:1722-1728.

3. Marik PE, Corwin HL: Efficacy of red blood cell transfusion in the critically ill: a systematic review of the literature. Crit Care Med 2008, 36:2667-2674.

4. Gajic O, Rana R, Winters JL, Yilmaz M, Mendez JL, Rickman OB, O'Byrne MM, Evenson LK, Malinchoc M, DeGoey SR, Afessa B, Hubmayr RD, Moore SB: Transfusion-related acute lung injury in the critically ill: prospective nested case-control study. Am J Respir Crit Care Med 2007, 176:886-891.

5. Iscimen R, Cartin-Ceba R, Yilmaz M, Khan H, Hubmayr RD, Afessa B, Gajic O: Risk factors for the development of acute lung injury in patients with septic shock: an observational cohort study. Crit Care Med 2008, 36:1518-1522.

6. Hebert PC, Wells G, Blajchman MA, Marshall J, Martin C, Pagliarello G, Tweeddale M, Schweitzer I, Yetisir E: A multicenter, randomized, 
controlled clinical trial of transfusion requirements in critical care. Transfusion Requirements in Critical Care Investigators, Canadian Critical Care Trials Group. N Engl J Med 1999, 340:409-417.

7. Netzer G, Shah CV, Iwashyna TJ, Lanken PN, Finkel B, Fuchs B, Guo W, Christie JD: Association of $\mathrm{RBC}$ transfusion with mortality in patients with acute lung injury. Chest 2007, 132:1116-1123.

8. Gong MN, Thompson BT, Williams P, Pothier L, Boyce PD, Christiani DC: Clinical predictors of and mortality in acute respiratory distress syndrome: potential role of red cell transfusion. Crit Care Med 2005, 33:1191-1198.

9. Rivers E, Nguyen B, Havstad S, Ressler J, Muzzin A, Knoblich B, Peterson E, Tomlanovich M, Early Goal-Directed Therapy Collaborative Group: Early goal-directed therapy in the treatment of severe sepsis and septic shock. N Engl J Med 2001, 345:1368-1377.

10. Hayes MA, Timmins AC, Yau EH, Palazzo M, Hinds CJ, Watson D: Elevation of systemic oxygen delivery in the treatment of critically ill patients. $N$ Engl J Med 1994, 330:1717-1722.

11. Gattinoni L, Brazzi L, Pelosi P, Latini R, Tognoni G, Pesenti A, Fumagalli R: A trial of goal-oriented hemodynamic therapy in critically ill patients. $\mathrm{SvO}_{2}$ Collaborative Group. N Engl J Med 1995, 333:1025-1032.

12. Dellinger RP, Levy MM, Carlet JM, Bion J, Parker MM, Jaeschke R, Reinhart $K$, Angus DC, Brun-Buisson C, Beale R, Calandra T, Dhainaut JF, Gerlach H, Harvey M, Marini JJ, Marshall J, Ranieri M, Ramsay G, Sevransky J, Thompson BT, Townsend S, Vender JS, Zimmerman JL, Vincent JL, International Surviving Sepsis Campaign Guidelines Committee; American Association of Critical-Care Nurses; American College of Chest Physicians; American College of Emergency Physicians; Canadian Critical Care Society; European Society of Clinical Microbiology and Infectious Diseases; European Society of Intensive Care Medicine; European Respiratory Society; International Sepsis Forum; Japanese Association for Acute Medicine; Japanese Society of Intensive Care Medicine; Society of Critical Care Medicine; Society of Hospital Medicine; Surgical Infection Society; World Federation of Societies of Intensive and Critical Care Medicine: Surviving Sepsis Campaign: international guidelines for management of severe sepsis and septic shock: 2008. Crit Care Med 2008, 36:296-327.

13. Napolitano LM, Kurek S, Luchette FA, Corwin HL, Barie PS, Tisherman SA, Hebert PC, Anderson GL, Bard MR, Bromberg W, Chiu WC, Cipolle MD, Clancy KD, Diebel L, Hoff WS, Hughes KM, Munshi I, Nayduch D, Sandhu R: Clinical practice guideline: red blood cell transfusion in adult trauma and critical care. Crit Care Med 2009, 37:3124-3157.

14. Reade MC, Huang DT, Bell D, Coats TJ, Cross AM, Moran JL, Peake SL, Singer $M$, Yealy DM, Angus DC: Variability in management of early severe sepsis. Emerg Med J 2010, 27:110-115.

15. Mikkelsen ME, Gaieski DF, Goyal M, Miltiades AN, Munson JC, Pines JM, Fuchs BD, Shah CV, Bellamy SL, Christie JD: Factors associated with nonadherence to early goal-directed therapy in the ED. Chest 2010, 138:551-558.

16. Wiedemann HP, Wheeler AP, Bernard GR, Thompson BT, Hayden D, deBoisblanc B, Connors AF Jr, Hite RD, Harabin AL: Comparison of two fluid-management strategies in acute lung injury. N Engl I Med 2006, 354:2564-2575.

17. Wheeler AP, Bernard GR, Thompson BT, Schoenfeld D, Wiedemann HP, deBoisblanc B, Connors AF Jr, Hite RD, Harabin AL: Pulmonary-artery versus central venous catheter to guide treatment of acute lung injury. N Engl J Med 2006, 354:2213-2224.

18. Schoenfeld DA, Bernard GR: Statistical evaluation of ventilator-free days as an efficacy measure in clinical trials of treatments for acute respiratory distress syndrome. Crit Care Med 2002, 30:1772-1777.

19. Mast AE, Schlumpf KS, Wright DJ, Custer B, Spencer B, Murphy EL, Simon TL: Demographic correlates of low hemoglobin deferral among prospective whole blood donors. Transfusion 2010, 50:1794-1802.

20. Angus DC, Linde-Zwirble WT, Lidicker J, Clermont G, Carcillo J, Pinsky MR: Epidemiology of severe sepsis in the United States: analysis of incidence, outcome, and associated costs of care. Crit Care Med 2001, 29:1303-1310.

21. Erickson SE, Shlipak MG, Martin GS, Wheeler AP, Ancukiewicz M, Matthay MA, Eisner MD: Racial and ethnic disparities in mortality from acute lung injury. Crit Care Med 2009, 37:1-6.

22. Long J: Regression Models for Categorical and Limited Dependent Variables Thousand Oaks, CA: Sage Publications; 1997.

23. Royston P: Multiple imputation of missing values. Stata J 2004, 4:227-241
24. Raghunathan TE: What do we do with missing data? Some options for analysis of incomplete data. Annu Rev Public Health 2004, 25:99-117.

25. van Buuren S: Multiple imputation of discrete and continuous data by fully conditional specification. Stat Methods Med Res 2007, 16:219-242.

26. Rubin DB: Inference and missing data. Biometrika 1976, 63:581-592.

27. Kor DJ, Gajic O: Blood product transfusion in the critical care setting. Curr Opin Crit Care 2010, 16:309-316.

28. Marik PE, Sibbald WJ: Effect of stored-blood transfusion on oxygen delivery in patients with sepsis. JAMA 1993, 269:3024-3029.

29. Fernandes CJ Jr, Akamine N, De Marco FV, De Souza JA, Lagudis S, Knobel E: Red blood cell transfusion does not increase oxygen consumption in critically ill septic patients. Crit Care 2001, 5:362-367.

30. Conrad SA, Dietrich KA, Hebert CA, Romero MD: Effect of red cell transfusion on oxygen consumption following fluid resuscitation in septic shock. Circ Shock 1990, 31:419-429.

31. El-Masri MM, Hammad TA, McLeskey SW, Joshi M, Korniewicz DM: Predictors of nosocomial bloodstream infections among critically ill adult trauma patients. Infect Control Hosp Epidemiol 2004, 25:656-663.

32. Malone DL, Dunne J, Tracy JK, Putnam AT, Scalea TM, Napolitano LM: Blood transfusion, independent of shock severity, is associated with worse outcome in trauma. J Trauma 2003, 54:898-907.

33. Steffes CP, Bender JS, Levison MA: Blood transfusion and oxygen consumption in surgical sepsis. Crit Care Med 1991, 19:512-517.

34. Silliman CC: The two-event model of transfusion-related acute lung injury. Crit Care Med 2006, 34(5 Suppl):S124-S131.

35. Silliman CC, Voelkel NF, Allard JD, Elzi DJ, Tuder RM, Johnson JL, Ambruso DR: Plasma and lipids from stored packed red blood cells cause acute lung injury in an animal model. J Clin Invest 1998, 101:1458-1467.

36. Hovav T, Yedgar S, Manny N, Barshtein G: Alteration of red cell aggregability and shape during blood storage. Transfusion 1999, 39:277-281.

37. Tsai $A G$, Cabrales $P$, Intaglietta M: Microvascular perfusion upon exchange transfusion with stored red blood cells in normovolemic anemic conditions. Transfusion 2004, 44:1626-1634.

38. d'Almeida MS, Gray D, Martin C, Ellis CG, Chin-Yee IH: Effect of prophylactic transfusion of stored $\mathrm{RBCS}$ on oxygen reserve in response to acute isovolemic hemorrhage in a rodent model. Transfusion 2001, 41:950-956.

39. Kiraly LN, Underwood S, Differding JA, Schreiber MA: Transfusion of aged packed red blood cells results in decreased tissue oxygenation in critically injured trauma patients. J Trauma 2009, 67:29-32.

40. Purdy FR, Tweeddale MG, Merrick PM: Association of mortality with age of blood transfused in septic ICU patients. Can J Anaesth 1997, 44:1256-1261.

\section{doi:10.1186/cc10458}

Cite this article as: Parsons et al:: Red blood cell transfusion and outcomes in patients with acute lung injury, sepsis and shock. Critical Care 2011 15:R221.

\section{Submit your next manuscript to BioMed Central and take full advantage of:}

- Convenient online submission

- Thorough peer review

- No space constraints or color figure charges

- Immediate publication on acceptance

- Inclusion in PubMed, CAS, Scopus and Google Scholar

- Research which is freely available for redistribution

Submit your manuscript at www.biomedcentral.com/submit
C Biomed Central 